\title{
Pelatihan Servis Sepeda Motor Injeksi Mekanik Bengkel Konvensional Di Kabupaten Solok Selatan
}

\author{
Erzeddin Alwi ${ }^{1}$, Hendra Dani Saputra ${ }^{2}$, Wanda Afnison ${ }^{3}$ \\ ${ }^{123}$ Jurusan Teknik Otomotif/Fakultas Teknik/Universitas Negeri Padang \\ *)Corresponding author, $\equiv$ endradani@ft.unp.ac.id
}

Revisi 03/06/2019;

Diterima 15/06/2019;

Publish 08/08/2019

Kata kunci:Kompetensi, Siswa,Pelatihan,Teknolologi Sepeda Motor

\begin{abstract}
Abstrak
Tingginya tingkat penjualan sepeda motor di Indonesiamasih memberikan banyak permasalahan bagi pelaku bisnis otomotif, dalam hal ini ketersediaan bengkel servis yang mumpuni dengan perkembangan teknologi otomotif saat ini. Banyak di temui bengkel yang belum paham akan teknologi sepeda motor khususnya teknologi Injeksi. Bengkel servis sepeda motor dan pelaku bisnis konvensional merupakan kelompok yang sangat rentan termakan dampak lambannya proses transfer teknologi ini.Berdasarkan Observasi yang dilakukan kendaraan roda 2 (sepeda motor) merupakan moda transportasi utama yang menopang kegiatan keseharian warga dan penopangperekonomian warga dalam mengirim hasil produk pertanian di kenagarian kapau alam pauh duo di kabupaten Solok selatan. Oleh karena itu diperlukan bengkel servis teknologi terbaru (injeksi) agar kondisi sepeda motor tetap dalam kondisi fit dan prima. Bengkel sepeda motor yang ada rata-rata mereka memiliki permasalahan yaitu sulitnya bagi mereka untuk mendapatkan Up-date teknologi terbaru sepeda motor, sehingga apabila ada kerusakan pada kendaraan keluaran terbaru (5 tahun terakhir) mereka lebih memilih untuk menolak. Ini terjadi lantaran memang para mekanik bengkel bukanlah orang yang memiliki latar belakang pendidikan seorang mekanik.Program pelatihan bertujuan untuk memberikantransfer of knowledge kepada mekanik, terutama teknologi terbaru sepeda motor. Sehingga output yang dihasilkan berupa kualitas pelayanan dan kompetensi mekanik menjadi lebih baik
\end{abstract}

This is an open access article distributed under the Creative Commons Attribution License, which permits unrestricted use, distribution, and reproduction in any medium, provided the original work is properly cited. (C2019 by author(s) 


\section{Suluah Bendang: Jurnal Ilmiah Pengabdian Kepada Masyarakat}

Vol.19, No.1, 2019

Erzeddin Alwi, Hendra Dani Saputra, Wanda Afnison

\section{PENDAHULUAN}

\section{AnalisisSituasi}

Teknologi otomotif semakin berkembangdengan pesat. Hal ini dapat dilihat dengan tingginya tingkat persaingan antar produsen pengahsail sepeda motor. Menurut data yang dihimpun Asosiasi Industri Sepeda Motor Indonesia (AISI) pada tahun 2015-2016 terjadi peningkatan jumlah penjualan sepeda motor sekitar 4,6\% atau meningkat sebanyak 5,8 juta unit untuk satu tahun. Tingginya tingkat penjualan dan perkembangan teknologi sepeda motor memberikan permasalahan bagi pelaku bisnis otomotif itu sendiri. Salah satu permasalahan yang sering terjadi adalah lambannya penyerapan kemajuan teknologi sampai ke tangan pengguna. Bengkel servis sepeda motor dan pelaku bisnis kalangan bawah merupakan kelompok yang sangat rentan termakan dampak lambannya proses transfer teknologi ini. Keadaan ini secara tidak langsung berdampak kepada pergerakan ekonomi yang lamban di kalangan bawah dikarenakan mereka kurang mendapatkan akses (pelatihan dan akses sumber referensi teknologi terbaru). Keadaan ini seharusnya menjadi perhatian khusus bagi kalangan atas para pegiat bisnis otomotif dan juga praktisi/akademisi terkait agar pesatnya perkembangan teknologi yang dihasilkan dapat memberikan dampak pertumbuhan ekonomi yang pesat juga bagi pelaku bisnis kalangan bawah.

Kenagarian Kapau Alam Pauh Duo merupakan salah satu nagari di Kecamatan Pauh Duo, Kabupaten Solok Selatan dengan jumlah penduduk sekitar 3.127 orang. Nagari Kapau Alam Pauh Duo memiliki luas $60.400 \mathrm{~m} 2$ yang di dominasi oleh area pertanian lahan kering (sawah) 308,75 Ha dan lahan basah (sawah) 109,40 Ha. Kondisi topografi seperti ini menjadikan dominan warga masyarakat kenagarian Kapau Alam Pauh Duo berprofesi sebagai petani disamping sektor perdagangan, industry rumah tangga dan wisata. Lokasi Kenagarian Kapau Alam Pauh Duo terletak $\pm 136 \mathrm{Km}$ dari Ibukota Provinsi, $\pm 130 \mathrm{Km}$ dari Ibu Kota Kabupaten dan $\pm 5 \mathrm{Km}$ dari Ibu Kota Kecamatansedangkan detail letak lokasi kegiatan Pengabdian masyarakat dari lokasi kampus UNP dapat dilihat dari peta berikut:

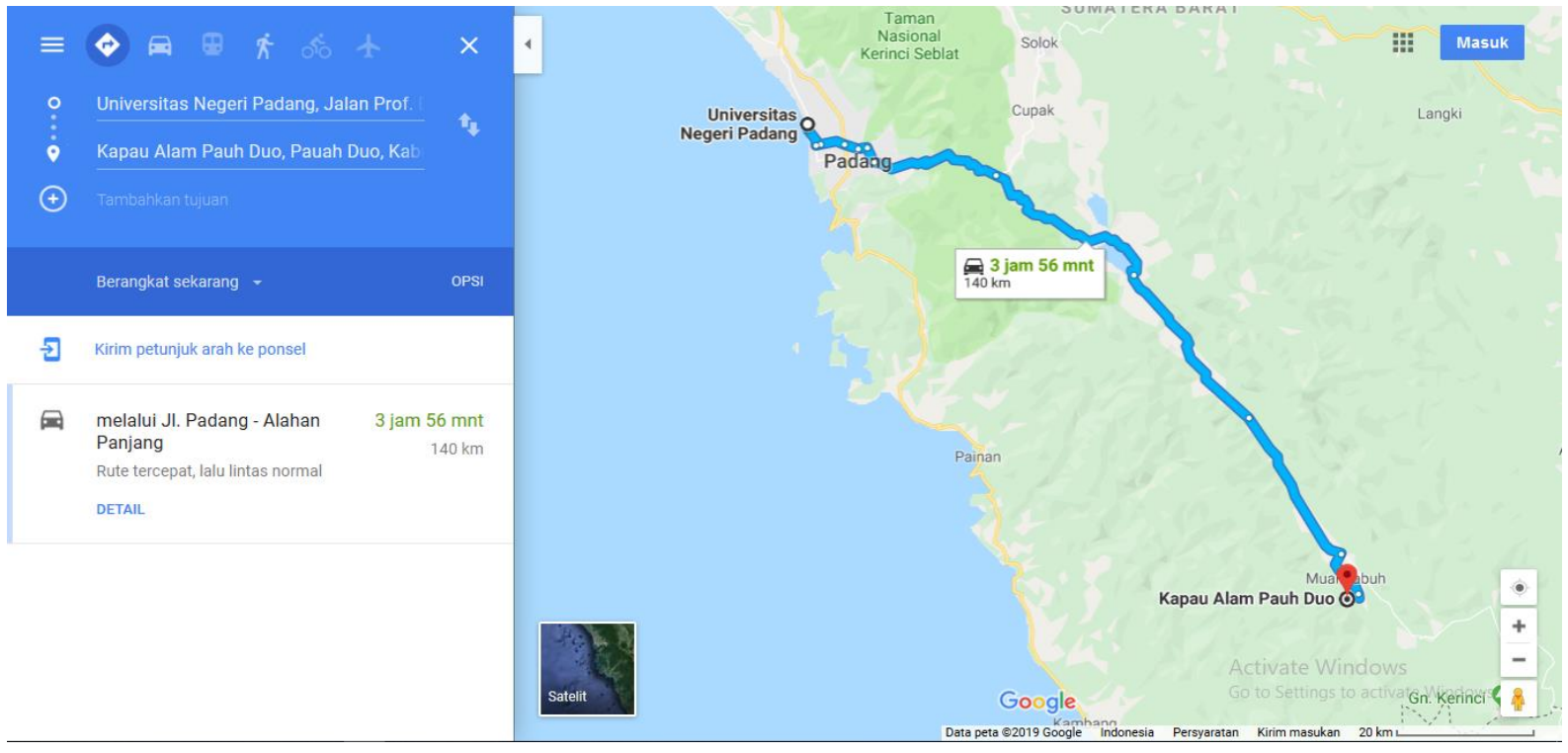

Gambar 1: Peta Lokasi Nagari Kenagarian Kapau Alam Pauh Duo - Universitas Negeri Padang.

Moda transportasi merupakan suatu hal yang sangat vital fungsinya bagi masyarakat. Kendaraan roda 4 dan 2 berfungsi sebagai moda transportasi utama yang menopang perekonomian warga dalam mengirim hasil produk pertanian. Selain sebagai pengangkut hasil 
pertanian, mayoritas warga juga menggunaan sepeda motor dalam kesehariannya. Selain dapat menghemat waktu dan aksesibilitas yang mudah, penggunaan sepeda motor juga dinilai lebih hemat biaya dibanding menggunakan transportasi umum. Banyaknya jumlah sepeda motor yang digunakan masyarakat secara tidak langsung berdampak kepada pergerakan perekonomian warga. Dari hasil survei awal yang dilakukan, tim mendapati setidaknya 11 bengkel sepeda motor di Kenagarian Kapau Alam Pauh Duo. Bengkel-bengkel sepeda motor di Kenagarian Kapau Alam Pauh Duo, rata-rata masih belum mampu untuk melakukan servis sepeda motor dengan teknologi injeksi. Disamping itu, peralatan yang mereka gunakan cenderung sederhana dan seadanya. Hampir tidak ditemui alat ukur digital dan alat ukur khusus lainnya. Dengan keadaan ini sudah barang tentu para mekanik akan kesulitan jika dihadapkan pada permasalahan sepeda motor terbaru yang sudah full electronic control. Berikut foto yang pengusul peroleh mengenai kondisi lapangan di bengkel mitra:
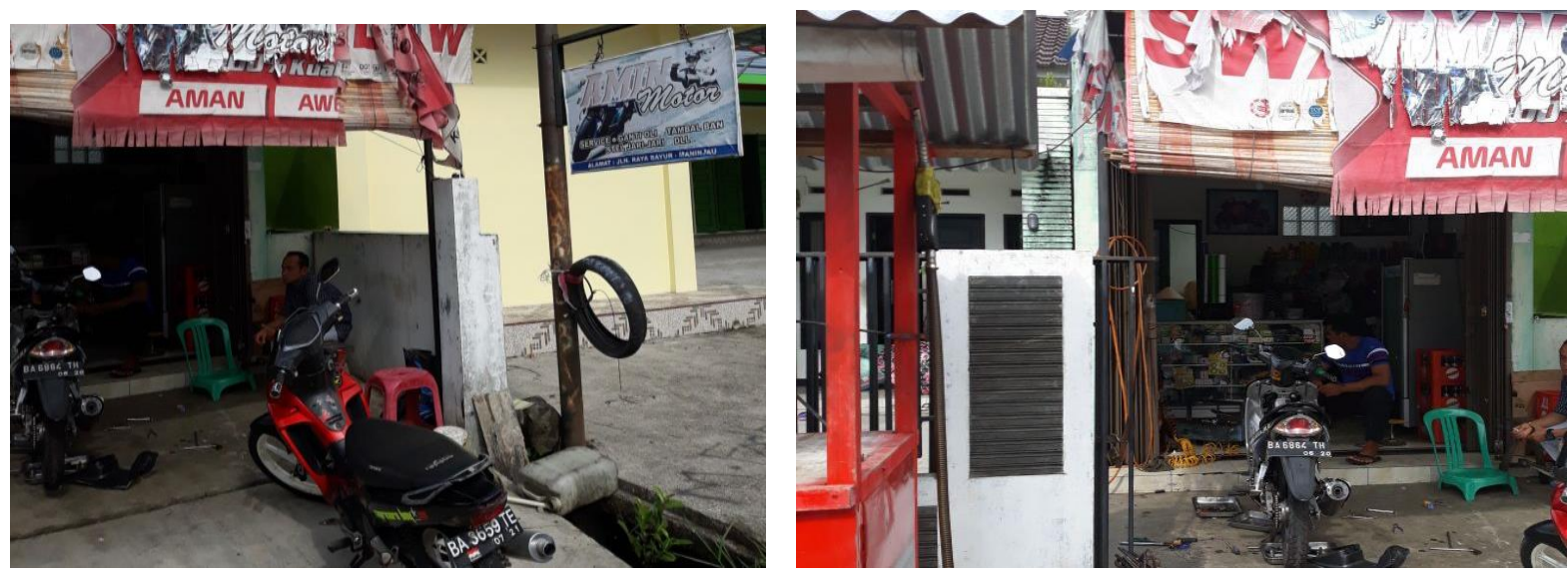

Gambar 2: Foto kondisi salah satu bengkel

Kondisi inilah yang menjadi latar belakang pengusul untuk mengajukan Program Kemitraan Masyarakat (PKM) dengan judul "Program Pelatihan Servis Sepeda Motor Injeksi (Fi) Bagi Mekanik Bengkel Konvensional Di Kenagarian Kapau Alam Pauh Duo Kabupaten Solok Selatan". Diharapkan dengan adanya program ini bisa menjadikan semakin tinggi motivasi bagi mekanik untuk mendapatkan ilmu teknologi Fuel Injection Sepeda motor.Sehinggamekanik mudahmenguasai dan memahami teknologi injeksi terutama teknologi terbaru sepeda motor. Sehingga output yang dihasilkan berupa kualitas servis sepeda motor yang bagus pelayanan dan kompetensi mekanik menjadi lebih baik. Saputra,H.D. (2018), memberikan gambaran bahwa motivasi memiliki pengaruh terhadap hasil belajar siswa memiliki. Sehingga dalam pelatihan ini mekanik yang mempunyai motivasi untuk ikut pelatihan akan mempunyai kompetensi yang tinggi pula.Sehingga mekanik yang menjadi peserta pelatihandapat menguasai teknologi Injeksi. Sehingga nantinya mekanik akan mampu melakukan servis injeksi sepeda motor secara mandiri.

\section{Solusi dan Target}

Solusi

Solusi yang diharapkan setelah pelatihan antara lain:

1. Pada Program Kemitraan Masyarakat (PKM) ini yang menjadi fokus utama adalah transfer of knowledge teknologi terbaru sepeda motor. Ini merupakan permasalahan utama yang 
ada pada bengkel mitra. Pada kegiatan ini akan diberikan pelatihan tentang teknologi terbaru sepeda motor seperti: pelatihan perawatan sepeda motor Electric Fuel Injection (EFI), penggunaan scan tool untuk identifikasi kerusakan, pemberian materi tentang teknologi ABS, Comby Brake dan teknologi terbaru sepeda motor lainnya.

2. Melaui kegiatan Program Kemitraan Masyarakat (PKM) ini mekanik akan mendapatkan hal baru dalam kemajuan teknologi sepeda motor. Tidak hanya sampai disana mekanik juga dapat mempraktekannya langsung pada sesi kegiatan praktikum. Sehingga dapat dipastikan kegiatan ini mampu meng Up-gradeskil/kemampuan mekanik.

3. Pada kegiatan ini juga akan dibekali dengan penggunaan alat ukur digital. Ini menjadi wajib karena hampir seluruh sistem pada sepeda motor terbaru menggunakan alat ukur digital sebagai pendeteksi kerusakan dan kondisi peformanya. Jadi dapat dipastikan tanpa pengetahuan penggunaan peralatan ukur digital mekanik tidak bisa berbuat banyak dalam menyelesaikan permasalahan pada kendaraan

4. Selama berlangsungnya kegiatan pengabdian Program Kemitraan Masyarakat (PKM), peserta (mekanik) diberikan panduan berupa materi pelatihan dan job sheet dalam bekerja. Sehingga setiap detail proses pekerjaan dapat dilakukan dengan baik dan terukur.

Pada pelatihan ini diharapkan mekanik mampu membaca sensor-sensor yang ada pada sepeda motor dan mampu membaca kode-kode lampu kerusakan berupa kode MIL (Mallfunction Indicator Lamp).

Tabel 1. Kode lampu MIL sepeda motor Honda

\begin{tabular}{ll}
\hline Jumlah Kedipan & \multicolumn{1}{c}{ Kode Gangguan } \\
\hline 1 kedipan & Manifold Absolute Pressure (MAP) \\
7 Kedipan & Engine Oil Temperature (EOT) \\
& Engine Coolant Temperature (ECT) \\
& Throttle Position (TP) \\
8 Kedipan & Intake Air Temperature (IAT) \\
9 Kedipan & Injector \\
12 Kedipan & O2 Sensor \\
21 Kedipan & Idle Air Control Valve \\
29 Kedipan & (IACV) \\
29 Kedipan & Engine Control Module (ECM) \\
33 Kedipan & \\
& Crank Position Sensor (CKP) \\
52 Kedipan & Bank Angle Sensor \\
\hline
\end{tabular}

Sehingga mekanik mampu mempunyai skill/ keahlian membaca dan memberikan solusi terhadap kerusakan yang terjadi pada sepeda motor.

Target

Dari program pengabdian masyarakat ini diharapkan tercapainya target luaran yang sudah dirumuskan. Berupa transfer of knowledge teknologi terbaaru sepeda motor dan peningkatan kemampuan mekanik dalam melakukan servis, perawatan dan perbaikan sepeda motor injeksi.

\section{METODE PELAKSANAAN}

\section{Tempat dan Waktu}


Kegiatan Pengabdian dilakukan kepada35 orang mekanik Sepeda Motor konvensional yang ada di Kenagarian Kapau Alam Pauh Duo kabupaten Solok Selatan.

\section{Khalayak Sasaran}

Kegiatan Pengabdian ditujukan kepada35 orang mekanik Sepeda Motor konvensional yang ada di Kenagarian Kapau Alam Pauh Duo kabupaten Solok Selatan.

\section{Metode Pengabdian}

Dalam pelaksaan Pengabdian digunakan metode-metode sebagai berikut:

\section{Metode Presentasi dan Diskusi}

Pelaksanaanya menggunakan teknik penyajian informasi berupa informasi umum tentang teori sepeda motor mesin konvensional. Selanjutnya teori mesin sepeda motor teknologi terbaru (Injeksi). Lapisa, R., Basri. I.Y.,Arif, A., dkk.(2017) memberikan gambaran jelas bagaimana presentasi. [3] Kemudian diberikan beberapa kesempatan memberikan pertanyaan kepada baik dari siswa maupaun dari instruktur seputar pengetahuan teknologi sepeda motor. Metode presentasi merupakan salah media yang digunakan untuk transfer of knowledgetentang teknologi injeksi sepeda motor. Dengan media presentasi yang menarik akan memudahkan peserta untuk memahami teori-teori pendukung yang ada pada teknologi injeksi sepeda motor. Sehingga akan mempermudah dalam praktek langsung tentang teknologi sepeda motor injeksi. Saputra,H.D. (2018) memberikan gambaran jelas dengan media yang valid dan reliabel akan menghasilkan efektifitas pembelajaran dalam hal ini penyerapan ilmu teknologi injeksi sepeda motor selama pelatihan.

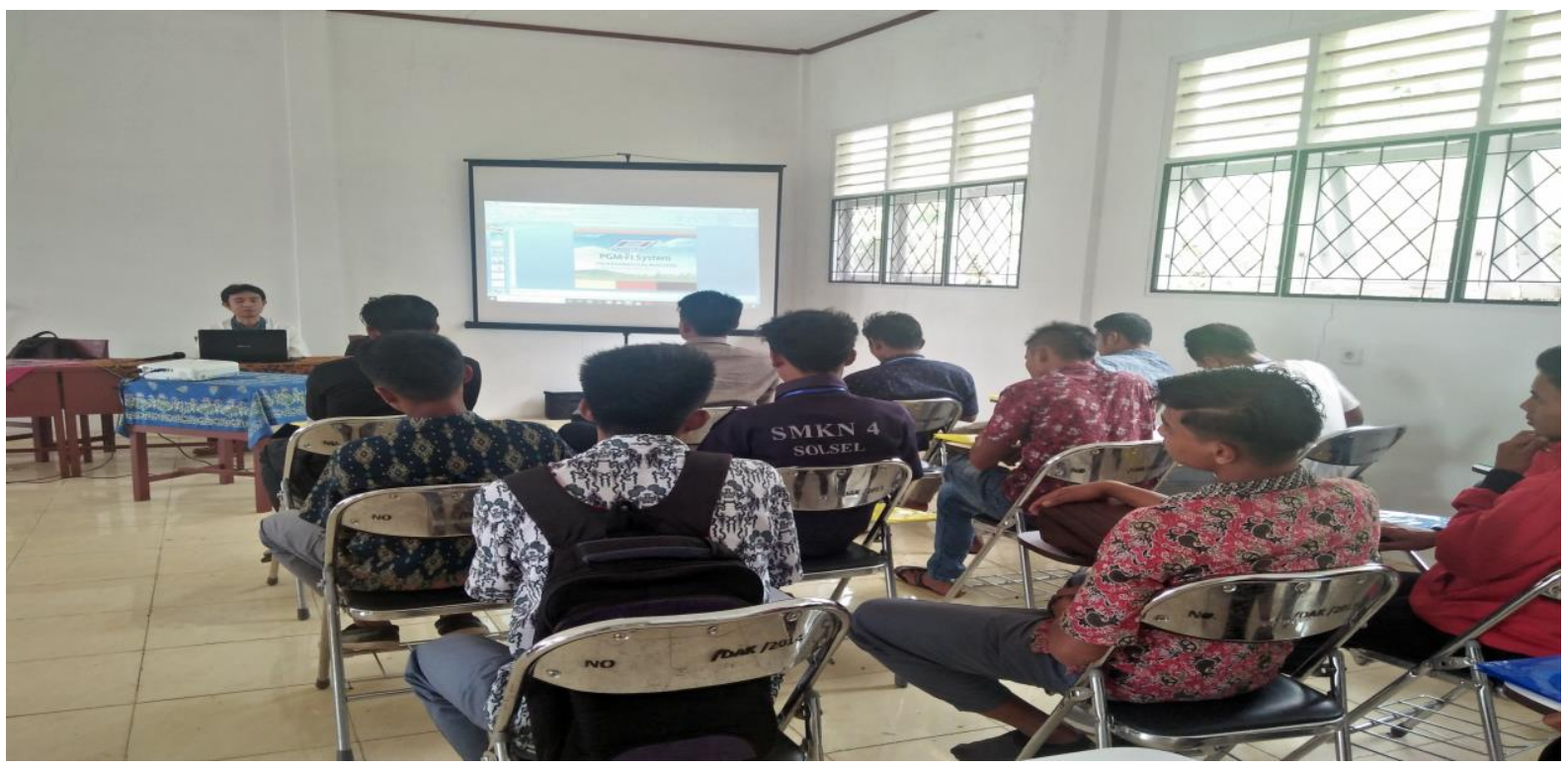

Gambar 3: Penyajian materi teknologi sepeda motor

\section{Metode Praktek Langsung}

Instruktur mendemontrasikan kepada peserta langkah-langkah tentang lokasi sensorsensor, cara melakukan reset sensor, kode-kode lampu kerusakan sepeda motor. Kemudian dilanjutkan dengan praktek langsung cara melakukan reset terhadap sensor-sensor sepeda 


\section{Suluah Bendang: Jurnal Ilmiah Pengabdian Kepada Masyarakat}

Vol.19, No.1, 2019

Erzeddin Alwi, Hendra Dani Saputra, Wanda Afnison

motor Selanjutnya diberikan kesempatan kepada peserta untuk berlatih dan melakukan

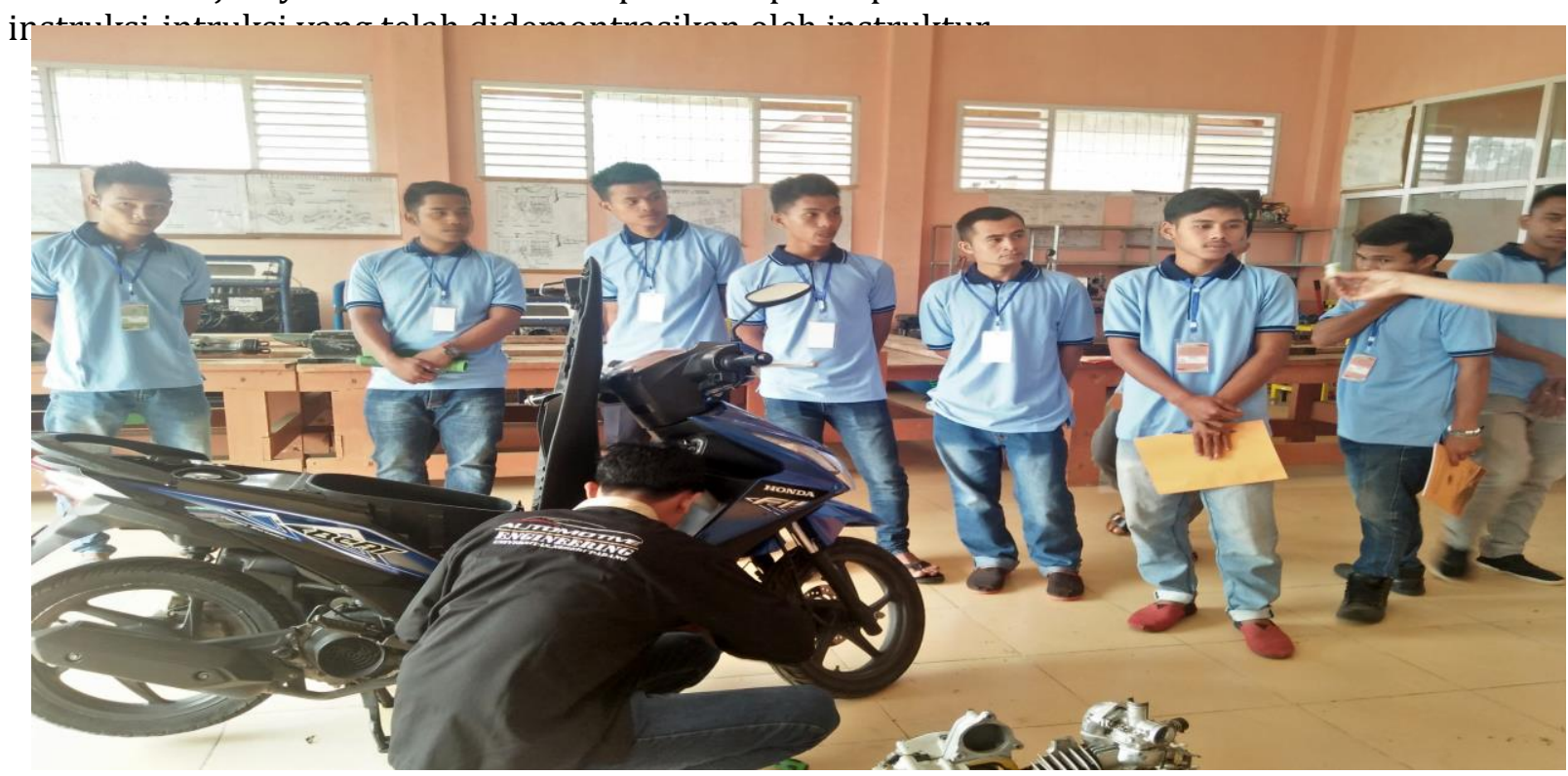

Gambar 4.Kegiatan mendemontrasikan dan praktek langsung lokasi sensor-sensor sepeda motor

Alwi, E., Hidayat, N., Afnison, W., \& Yuvenda, D. (2018). menyatakan bahwa diperlukan praktek langsung teknologi injeski sepeda motor untuk mengupgrade dan meningkatkan pengetahuan dan keterampilan peserta pelatihan. Sehingga dengan pelatihan yang dilakukan, peserta dapat memahami dan melakukan secara mandiri langkah-langkah pengecekan sensor dan melakukan reset (kembali kekondisi ) awal sepeda motor..

\section{MetodeEvaluasi}

Evaluasi saat kegiatan

Kehadiran Peserta

Peserta yang mengikuti pelatihan berjumlah 35 orang peserta. Pelatihan dipadatkan 3 hari mulai jumat-sabtu dan minggu tanggal 20-22 September 2019. Dimulai pukul 08.00-18.00 WIB. Selama pelaksanaan pelatihan peserta dengan penuh semangat mengikuti pelatihan dan penuh kedisiplinan mengikuti semua materi pelatihan.

\section{Keiingintahuan Peserta}

Selama pelatihan diberikan peserta sangat serius mendengarkan materi tentang teknologi sepeda motor, tentang sensor-sensor pada sepeda motor dan materi kode lampu kerusakan pada sepeda motor. Disamping itu peserta sangat ingin tahu dan sangat ingin mencoba melakukan bagaimaa cara membaca dan melakukan reset. Peserta tiak ragu untuk bertanya jika ada hal-hal yang masih belumm dipahaminya. 
Berikut ini merupakan tahapan dan dokumentasi kegiatan pelatihan yang dilakukan:

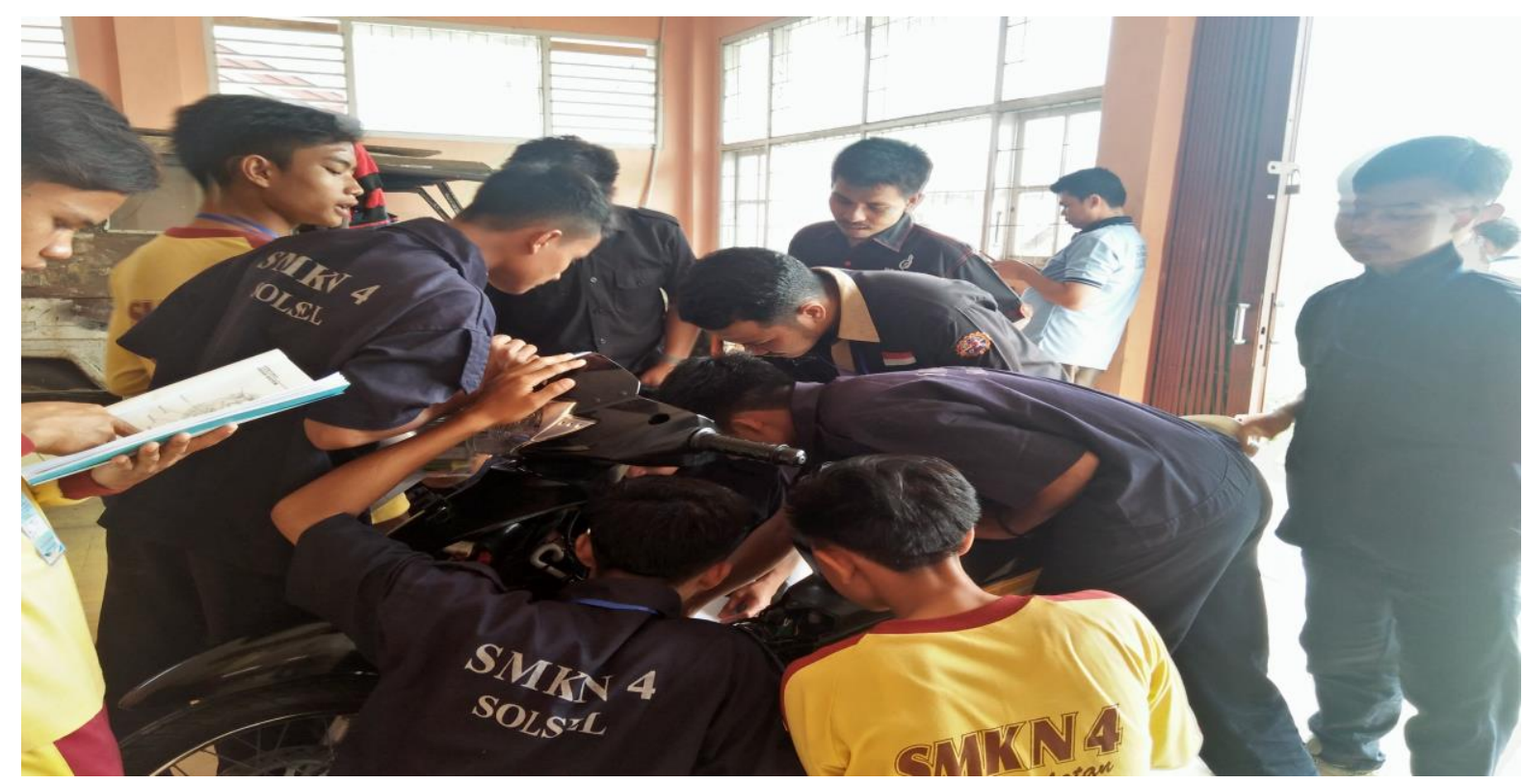

Gambar 5.Praktek langsung tentang reset sensor sepeda motor injeksi

\section{HASIL DAN PEMBAHASAN}

\section{Hasil}

Berdasarkan hasil evaluasi awal dan akhir pelatihan, maka dapat diberikan kesimpulan bahwa peserta dengan penuh semangat mengikuti pelatihan dan penuh kedipsilinan mengikuti semua materi pelatihan Tingkat kedisiplinan peserta sangat tinggi. Dengan pelatihan yang dilakukan terjadi peningkatan pengetahuan dan kemampuan peserta tentang teknologi sepeda motor.hal ini dapat dilihat pada gambar grafik 6 berikut ini.

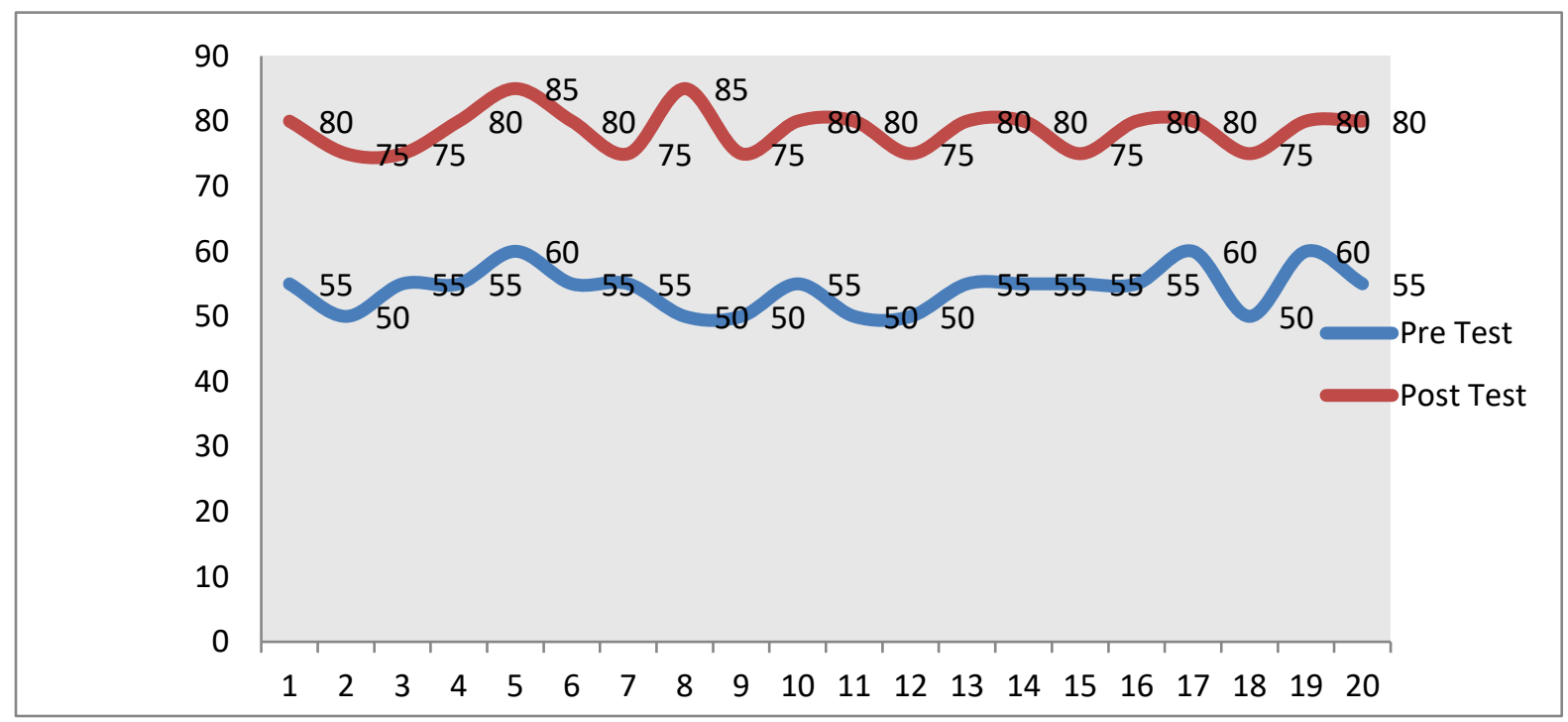




\section{Suluah Bendang: Jurnal Ilmiah Pengabdian Kepada Masyarakat}

Vol.19, No.1, 2019

Erzeddin Alwi, Hendra Dani Saputra, Wanda Afnison

Gambar 6.Grafik peningkatan pengetahuan peserta pelatihan
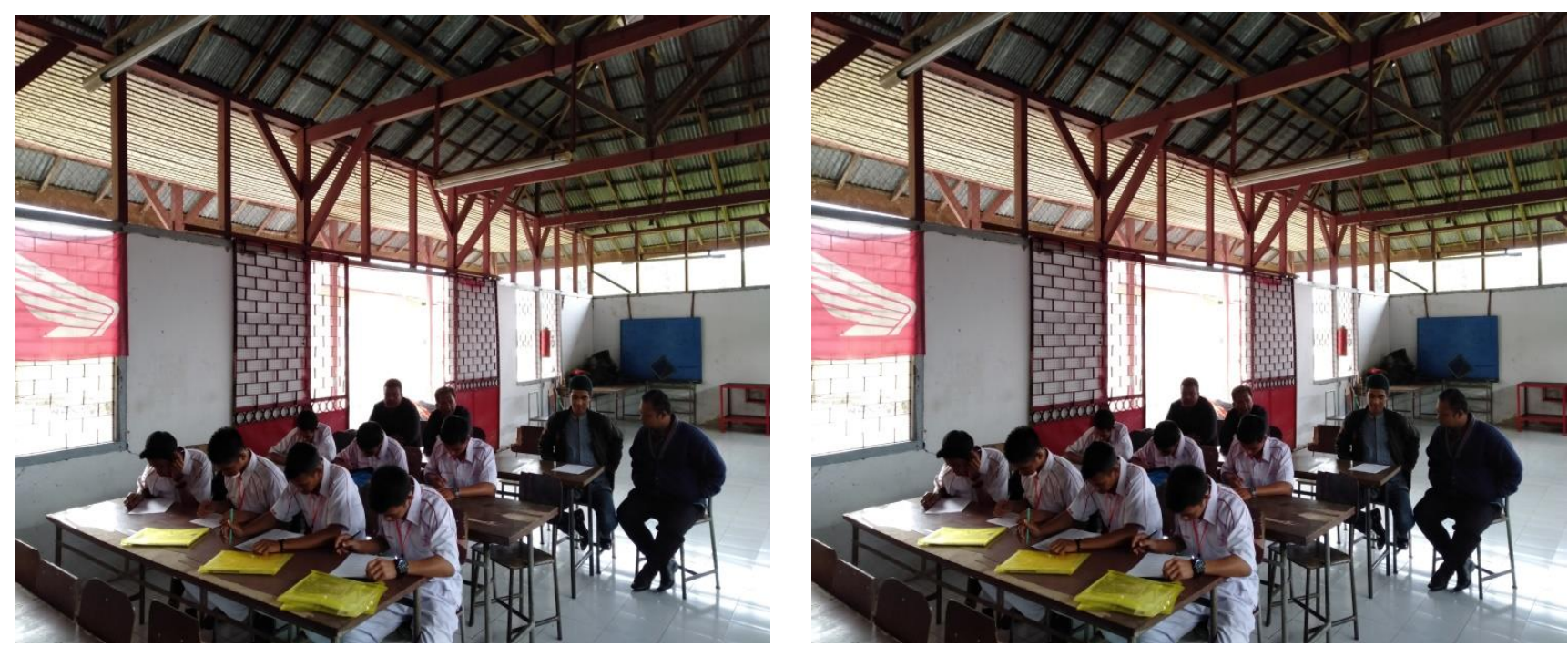

Gambar 6.Grafik peningkatan kompetensi pesrata pelatihan sepeda motor injeksi

\section{Pembahasan}

Kegiatan pelatihan teknologi sepeda motor telah mencapai sasaran yang sesuai dengan yang diharapkan. Hal ini dilihat dari hasil akhir nilai pengetahuan dan keterampilan yang telah diperoleh oleh peserta pelatihan. Peserta pelatihan mampu memahami, membaca, sensor-senor, membaca kode-kode kerusakan dan melakukan reset sepeda motor injeksi, Peserta pelathan juga berharap agar kegiatan pelatihan ini bisa diperpanjang, sehingga mereka bisa makin meningkatkan kemampuan peserta dalam pengetahuan teknologi sepeda motor. Komunikasi terjalin dengan baik antar instruktur dengan peserta pelatihan baik melalui media sosial, telepon maupun peserta datang ke kampus.

\section{KESIMPULAN}

Kegiatan pelatihan teknologi sepeda motor merupakan salah satu kegiatan pengabdian kepada masyarakat yang bertujuan untuk meningkatkan pengetahuan dan kemampuan ( kompetensi) peserta pelatihan dalam memahami dan melakukan perbaikan teknologi sepeda motor injeksi. Peserta pelatihan melaksanakan pelatihan dengan penuh disiplin manantusias. Sehingga mempermuudahkan peserta untuk mendapatkan pengatahuan dan keterampilan selama mengikuti pelatihan. Sehingga dengan pelatihan yang berjenjang sesudah pelatihan ini diharpkan peserta mampu secara mandiri melakukan service sepeda motor injeksi.

\section{DAFTAR PUSTAKA}

Alwi, E., Hidayat, N., Afnison, W., \& Yuvenda, D. (2018). Program Up-Grade Skill Service Sepeda Motor Bagi Mekanik Bengkel Pemula Di Jorong Koto Malintang. Pakar Pendidikan, 16(1), $\quad$ 16-21. 
Lapisa, R. B. (2017 Vol 17 (2).Peningkatan Kompetensi Siswa Melalui Pelatihan Auto CAD. INVOTEK: Jurnal Inovasi Vokasiona ldan Teknologi, 119-126.

Saputra, H. D. (2018). Pengaruh Motivasi Terhadap Hasil Belajar Siswa SMK. Invotek:Jurnal Inovasi Vokasional dan Teknologi, 25-30.

Saputra, H. D, N Nasrun, W Wakhinuddin (2018).Development of Web-Based Learning Media in Vocational Secondary School.VOLT: jurnal ilmiah Pendidikan teknik elektro, 37-41.

PT. Astra Honda Motor.2013, PGM-FI System (Programmed Fuel Injection System, Technical Service Division-Technical Training Dept. 